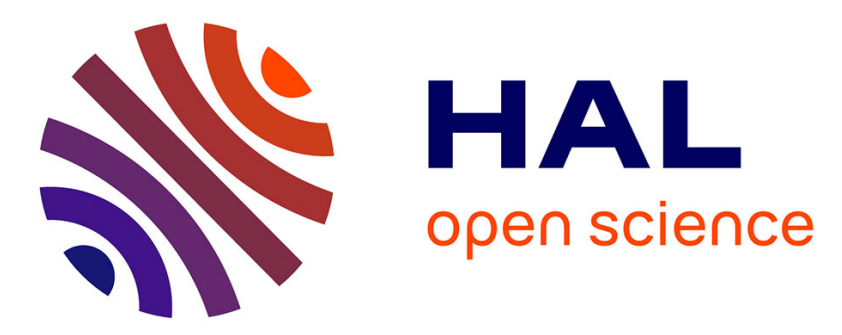

\title{
Efficient CO2 Sequestration by a Solid-Gas Reaction Enabled by Mechanochemistry: The Case of L-Lysine
}

Abdal-Azim Al-Terkawi, Frédéric Lamaty, Thomas-Xavier Métro

\section{To cite this version:}

Abdal-Azim Al-Terkawi, Frédéric Lamaty, Thomas-Xavier Métro. Efficient CO2 Sequestration by a Solid-Gas Reaction Enabled by Mechanochemistry: The Case of L-Lysine. ACS Sustainable Chemistry \& Engineering, 2020, 8 (35), pp.13159-13166. 10.1021/acssuschemeng.0c00217 . hal-02990604

\section{HAL Id: hal-02990604 https://hal.science/hal-02990604}

Submitted on 10 Nov 2020

HAL is a multi-disciplinary open access archive for the deposit and dissemination of scientific research documents, whether they are published or not. The documents may come from teaching and research institutions in France or abroad, or from public or private research centers.
L'archive ouverte pluridisciplinaire HAL, est destinée au dépôt et à la diffusion de documents scientifiques de niveau recherche, publiés ou non, émanant des établissements d'enseignement et de recherche français ou étrangers, des laboratoires publics ou privés. 


\title{
Efficient $\mathrm{CO}_{2}$ Sequestration by a Solid-Gas Reaction Enabled by Mechanochemistry: The Case of L-Lysine
}

\author{
Abdal-Azim Al-Terkawi, Frédéric Lamaty, and Thomas-Xavier Métro* \\ Cite This: https://dx.doi.org/10.1021/acssuschemeng.0c00217 \\ Read Online
}

ABSTRACT: This study describes an efficient and solvent-free method for the regioselective production of L-lysine ammonium $\varepsilon$ carbamate by ball-milling L-lysine under a $\mathrm{CO}_{2}$ atmosphere. The regioselective formation of $\mathrm{L}$-lysine ammonium $\varepsilon$-carbamate via this mechanochemical approach was confirmed by a complete analytical study, including ${ }^{1} \mathrm{H} \rightarrow{ }^{13} \mathrm{C}$ and ${ }^{1} \mathrm{H} \rightarrow{ }^{15} \mathrm{~N}$ cross polarization magic-angle spinning NMR measurements as well as liquid NMR analyses, powder X-ray diffraction measurements, thermal analyses, and elemental analyses. The time of milling, rotational speed, milling material, and liquid assistants were screened, while the reversibility of the process was assessed. The milling approach was compared with the synthesis in aqueous solutions and in the solid state without agitation. In addition to being regioselective, the synthesis by solvent-free mechanochemistry was found to be much faster than the other approaches while also producing less waste.

KEYWORDS: Mechanochemistry, Ball-milling, L-Lysine, Carbamate, $\mathrm{CO}_{2}$ conversion, $\mathrm{CO}_{2}$ storage, Regioselectivity, Reversibility

\section{INTRODUCTION}

The immense production of $\mathrm{CO}_{2}$, due to humans and industrial activities, and its steady accumulation in the atmosphere are significant causes of global warming, which is expected to reach $1.5{ }^{\circ} \mathrm{C}$ between 2030 and 2052, triggering climate-related risks for nature and humans. Therefore, a massive reduction or zero- $\mathrm{CO}_{2}$ emission is crucial to prevent further climate-related damages. ${ }^{1}$ In addition, $\mathrm{CO}_{2}$ is an abundant, economical, and renewable carbon source that could be captured and used for the production of various materials, thereby avoiding its greenhouse effect. ${ }^{2-7}$ For instance, $\mathrm{CO}_{2}$ is well-known to react with amines, leading to the formation of carbamic acids or ammonium carbamates depending on, among other factors, the structures of amines and solvents (Scheme 1). ${ }^{2,8,9}$

This reactivity has been utilized at the industrial scale to capture $\mathrm{CO}_{2}$ issuing from fossil fuel-burning power plants. ${ }^{10-14}$ Unfortunately, these processes are limited by their cost due to the energy needed at the $\mathrm{CO}_{2}$ regeneration step, equipment corrosion, volatility, and stability of the amines, along with

Scheme 1. Formation of a Carbamic Acid or an Ammonium Carbamate from an Amine and $\mathrm{CO}_{2}$

$\mathrm{R}-\mathrm{NH}_{2} \stackrel{\mathrm{CO}_{2}}{\longrightarrow} \begin{gathered}\mathrm{R}-\mathrm{NHCO}_{2} \mathrm{H} \text { or } \mathrm{R}-\mathrm{NHCOO}^{-+} \mathrm{H}_{3} \mathrm{~N}-\mathrm{R} \\ \text { carbamic acid ammonium carbamate }\end{gathered}$ environmental issues. ${ }^{11-17}$ While the predominant processes for capturing $\mathrm{CO}_{2}$ rely on the use of toxic alkanolamines as chemical sorbents, some research groups have studied the reactivity of $\mathrm{CO}_{2}$ with amino groups of innocuous $\alpha$-amino acids and their derivatives to form carbamates. ${ }^{18-23}$ Of note, the vast majority of these reactions are performed in a liquid phase, mostly using water as a solvent. Using a solvent is the standard approach to homogenize reaction mixtures and to facilitate agitation by traditional stirring systems, yet this lowers the theoretical maximum speed of reactions by moving the reactants away from each other. To the best of our knowledge, only one example of the solvent-free reactivity between amino acid derivatives and $\mathrm{CO}_{2}$ has been described in the literature: the group of Limbach has performed solid-state NMR studies on the formation of carbamates issuing from the exposition of solid poly-L-lysine to atmospheric $\mathrm{CO}_{2}{ }^{24,25}$ In this case, the reactivity between poly-L-lysine and $\mathrm{CO}_{2}$ may have been seriously hampered by mass transfer limitations. To avoid such limitations, many research groups have turned to mechanochemistry, predominantly ball-milling, performing an

Received: January 9, 2020

Revised: June 30, 2020 
extraordinarily wide array of reactions between solids in the total absence of solvents. ${ }^{26-30}$ Additionally, mechanochemistry is capable of modifying the selectivity when compared to solvent-based syntheses and giving access to otherwise inaccessible compounds. ${ }^{31}$ While mechanochemistry is now commonly used for the chemical transformation of solids sometimes involving liquids, it has been used only scarcely with gaseous reactants ${ }^{32}$ yet with very high efficiency in specific cases. ${ }^{33}$ Examples describing the use of ball-milling to convert $\mathrm{CO}_{2}$ are even rarer. ${ }^{34-38}$ In addition, L-lysine is an innocuous and essential $\alpha$-amino acid, produced at more than a million metric tons per year and is of paramount importance for animal feed, pharmaceutical, and cosmetic industries. ${ }^{39}$ This situation prompted us to study the reactivity of L-lysine with gaseous $\mathrm{CO}_{2}$ under ball-milling. The results of this approach were compared with syntheses in aqueous solutions and in the absence of both solvent and agitation. To the extent of our knowledge, the present work is the first study on carbamates formation by milling an amino acid with $\mathrm{CO}_{2}$.

\section{RESULTS AND DISCUSSION}

Reactivity and Selectivity. In a typical milling experiment, $500 \mathrm{mg}$ of commercially available L-lysine was milled in a planetary mill for $5 \mathrm{~h}$ under 5 bar of $\mathrm{CO}_{2}$ gas (a $20 \mathrm{~mL} \mathrm{Z \textrm {ZO } _ { 2 }}$ reactor containing $80 \mathrm{ZrO}_{2}$ balls of $5 \mathrm{~mm}$ diameter was used), leading to the formation of a white powder that was recovered directly from the milling reactor and first analyzed by thermogravimetry measurements. The corresponding thermoanalytical curve depicted a mass loss of $-12.4 \%$ between 75 and $175{ }^{\circ} \mathrm{C}$, which was attributed to the release of one $\mathrm{CO}_{2}$ molecule (calc. 12.42\%) from an ammonium-carbamate ion pair, thereby confirming the formation of the carbamate bond during milling (see Figure S3b). The mass loss observed up to $75{ }^{\circ} \mathrm{C}(-5.1 \%)$ was assigned to the release of one water molecule (calc. 5.08\%), indicating that the ammoniumcarbamate ion pair was obtained as a monohydrate $\left(0.5 \mathrm{H}_{2} \mathrm{O}\right.$ per one L-lysine molecule). These results were consolidated by the elemental analysis, which was in agreement with the formation of an ammonium carbamate monohydrate (see Figure S3 and Table S2 for details). The formation of a carbamate bond was further confirmed by ${ }^{1} \mathrm{H} \rightarrow{ }^{13} \mathrm{C}$ cross polarization magic-angle spinning (CP MAS) NMR spectrum that depicted a carbon signal at $\delta=165 \mathrm{ppm}$ (Figure 1, red spectrum).

Noteworthy, only one peak was observed in the carbamate region, strongly suggesting the newly formed carbamate bond was selectively installed on one of the two available positions only $\left(\alpha-\mathrm{NH}_{2}\right.$ or $\left.\varepsilon-\mathrm{NH}_{2}\right)$. This result was confirmed by a ${ }^{1} \mathrm{H} \rightarrow$ ${ }^{15} \mathrm{~N}$ CP MAS NMR experiment showing only one peak at $\delta=$ $88 \mathrm{ppm}$, corresponding to a nitrogen atom engaged in a carbamate bond (Figure 2, red spectrum).

On the ${ }^{1} \mathrm{H} \rightarrow{ }^{13} \mathrm{C}$ CP MAS NMR spectrum (Figure 1, red spectrum), the single carbon signal at $\delta=178 \mathrm{ppm}$ displaying a similar chemical shift to the signal of the L-lysine carboxylate $(\delta$ $=177 \mathrm{ppm}$, black spectrum) strongly suggested that the carbamate bond was not installed on $\alpha-\mathrm{NH}_{2}$ but on $\varepsilon-\mathrm{NH}_{2}$. These results were then compared with the L-lysine ammonium carbamate obtained by bubbling $\mathrm{CO}_{2}$ for $4 \mathrm{~h}$ into an aqueous solution of L-lysine $(500 \mathrm{mg}$ of L-lysine dissolved in $5 \mathrm{~mL}$ of $\mathrm{D}_{2} \mathrm{O} ; \eta=10 \mu \mathrm{L} / \mathrm{mg}$ ) followed by concentrating until dry to remove water. The ${ }^{1} \mathrm{H} \rightarrow{ }^{13} \mathrm{C} \mathrm{CP}$ MAS NMR spectrum of the corresponding L-lysine ammonium carbamate (Figure 1, purple spectrum) depicted a peak at $\delta=$
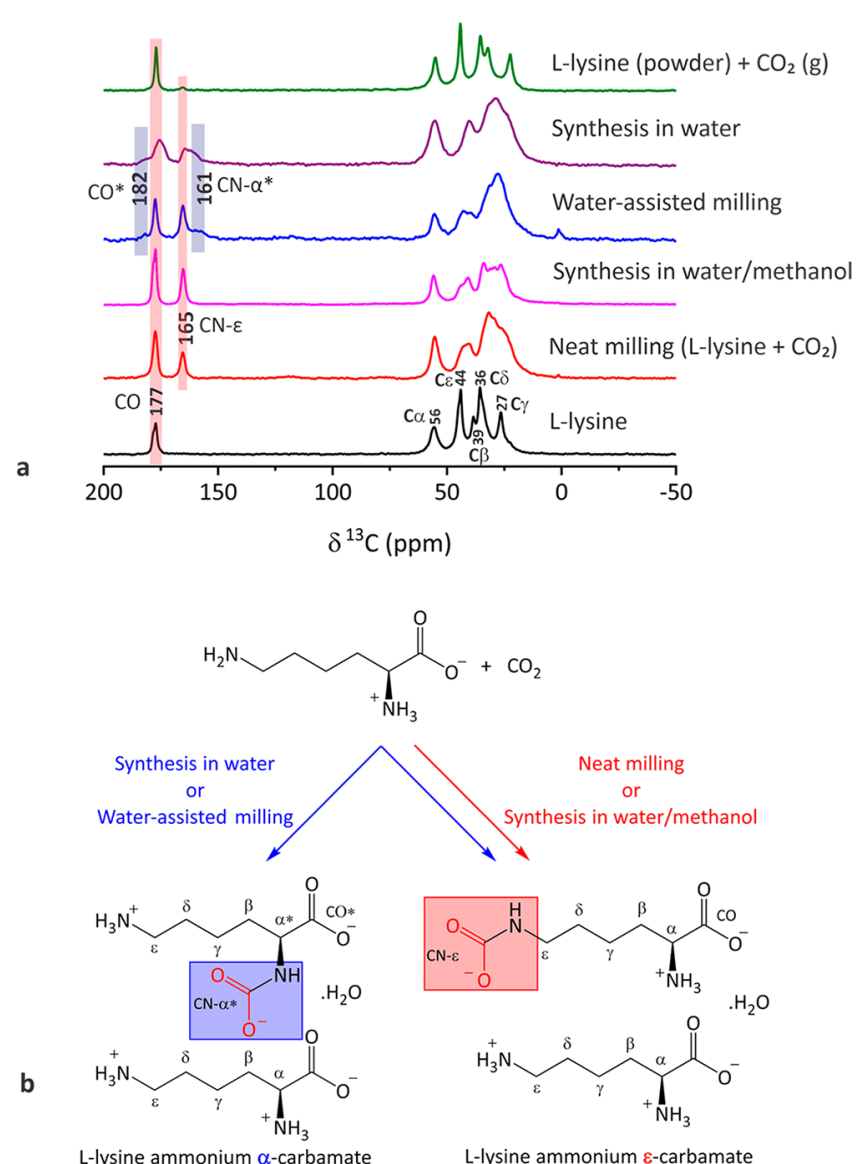

Figure 1. (a) ${ }^{1} \mathrm{H} \rightarrow{ }^{13} \mathrm{C}$ CP MAS NMR spectra of L-lysine (black spectrum) and spectra of the products obtained by the reaction of $\mathrm{L}-$ lysine with $\mathrm{CO}_{2}$ gas under neat-milling conditions (red spectrum), synthesis in water/methanol (magenta spectrum), water-assisted milling (blue spectrum), bubbling $\mathrm{CO}_{2}$ gas into an aqueous solution of L-lysine followed by water evaporation (purple spectrum), and storing L-lysine (powder) under a $\mathrm{CO}_{2}$ gas atmosphere for 15 days (green spectrum). (b) The proposed molecular structures of L-lysine ammonium $\varepsilon$-carbamate (obtained by neat-milling and synthesis in water/methanol methods) and L-lysine ammonium $\alpha$ - and $\varepsilon$ carbamates (obtained by water-assisted milling and synthesis in water methods). Color codes: the $\varepsilon$-carbamate bond is shaded in red, and the $\alpha$-carbamate bond is shaded in blue.

$165 \mathrm{ppm}$ and a high shoulder at $\delta=161 \mathrm{ppm}$, which are indicative of the formation of two different carbamates installed at the $\alpha-\mathrm{NH}_{2}$ and the $\varepsilon-\mathrm{NH}_{2}$ positions, contrary to neat-milling. This spectrum also depicted two signals corresponding to a carboxylate: a peak at $\delta=178 \mathrm{ppm}$ (similar to the carboxylate of L-lysine, Figure 1, black spectrum) and a shoulder at $182 \mathrm{ppm}$, which can be assigned to the carboxylate bearing a carbamate on the $\alpha-\mathrm{NH}_{2}$. As this latter peak is not visible on the ${ }^{1} \mathrm{H} \rightarrow{ }^{13} \mathrm{C}$ CP MAS NMR spectrum of the L-lysine ammonium carbamate obtained by neat-milling, this is an additional proof that neat-milling led to the formation of the L-lysine ammonium carbamate on the $\varepsilon$ $\mathrm{NH}_{2}$ position only (Figure 1, red spectrum). In addition to being a regioselective process, neat-milling provided L-lysine ammonium $\varepsilon$-carbamate in quantitative yields because, for every reaction condition screened (all the experimental conditions are summarized in Table S1), the obtained powders were analytically pure after being recovered directly from the milling reactor without further treatment. Due to the poor 


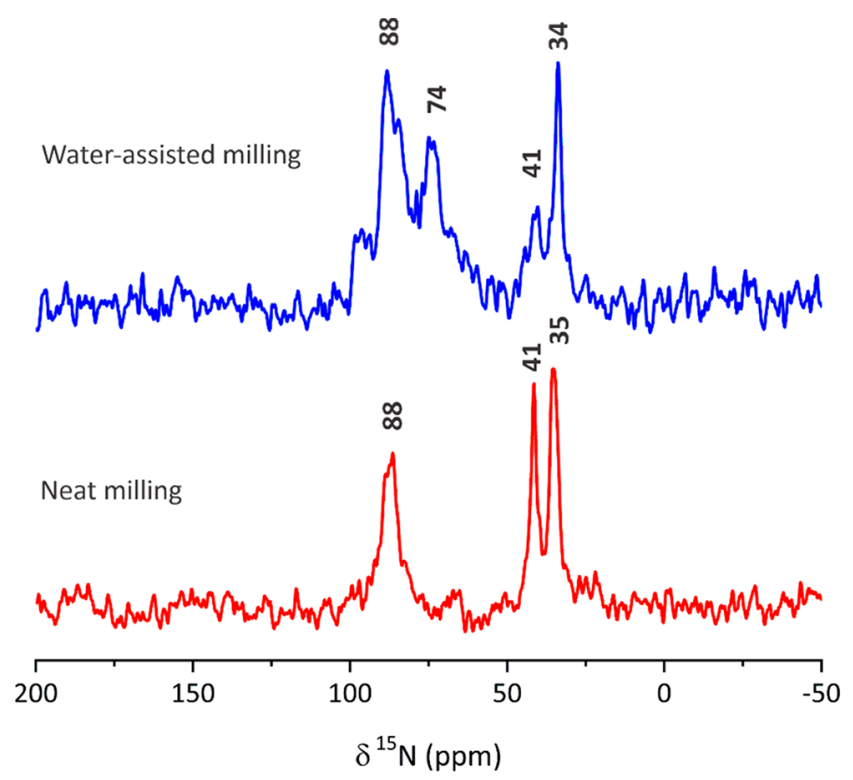

Figure 2. ${ }^{1} \mathrm{H} \rightarrow{ }^{15} \mathrm{~N}$ CP MAS NMR spectra of the products obtained by the reaction of L-lysine with $\mathrm{CO}_{2}$ gas under neat-milling conditions (red spectrum) and under water-assisted milling conditions ( $50 \mu \mathrm{L}$ of $\mathrm{H}_{2} \mathrm{O} / 500 \mathrm{mg}$ of L-lysine; $\eta=0.1 \mu \mathrm{L} / \mathrm{mg}$ ) (blue spectrum). The $\eta$ parameter is defined by the ratio of the volume of the liquid $(\mu \mathrm{L})$ to the total mass of solids (mg).

crystallinity of the obtained powders, $a b$ initio structure determination of the carbamates starting from the powder Xray diffraction (PXRD) data was unfortunately not possible. Efforts for improving the polycrystallinity or the growth of single crystals did not succeed so far. Neat milling was not the only strategy enabling to obtain L-lysine ammonium $\varepsilon$ carbamate regioselectively. Indeed, a patent authored by Bru in 1980 described the synthesis of L-lysine ammonium $\varepsilon$ carbamate by reacting $\mathrm{CO}_{2}$ with L-lysine solubilized in a $1: 5$ water/methanol mixture. ${ }^{40}$ Although the original paper did not provide any experimental proof of the regioselectivity of the reaction, in our hands, the corresponding protocol produced Llysine ammonium $\varepsilon$-carbamate regioselectively, as indicated by the ${ }^{1} \mathrm{H} \rightarrow{ }^{13} \mathrm{C} \mathrm{CP}$ MAS NMR spectrum (Figure 1, magenta spectrum). However, this strategy requires $\mathrm{MeOH}$ (a toxic solvent) and necessitates a greater experimental time than that of the neat-milling procedure. One could explain the selectivity of the reaction under neat-milling by the crystalline structure of L-lysine. Indeed, in the crystal structures reported by Harris and co-workers, ${ }^{41,42}$ L-lysine molecules are found as zwitterions, where the $\alpha$-nitrogen atom is protonated (as $\alpha-\mathrm{NH}_{3}$ ) while the $\varepsilon-\mathrm{NH}_{2}$ is not (but involved in a hydrogen-bonding network (HBN) with water); this difference could explain the higher reactivity of the $\varepsilon$-nitrogen atom. This selectivity related to the crystal structure of L-lysine is also a strong indication that the carbamate formation during neat-milling is a solidstate process and that the presence of crystallized water in Llysine hemihydrate is not sufficient to induce the formation of both $\alpha$ - and $\varepsilon$-carbamates. In contrast, the protophilic character of water could explain the nonselectivity of the formation of the carbamate when synthesis is performed in water. The selective formation of the $\varepsilon$-carbamate molecule in the water/methanol mixture could therefore be explained by precipitation/crystallization, which is known to be a potentially

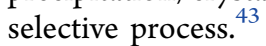

Speed of Reaction. The influence of the milling time on the formation of L-lysine ammonium $\varepsilon$-carbamate was next investigated (Table S1). To our delight, the conversion of $\mathrm{L}^{-}$ lysine was completed after a reduced milling time of only 5 min, indicating that the reaction is very rapid. Comparatively, synthesis in water was much slower, which could be explained by the formation of carbonate/bicarbonate ions as the kinetic products resulting from the reaction of water with $\mathrm{CO}_{2}$, as indicated by the typical carbon signals at about $\delta=160 \mathrm{ppm}$ (Figure 3, red ${ }^{13} \mathrm{C}$ NMR spectrum). Part of the speed

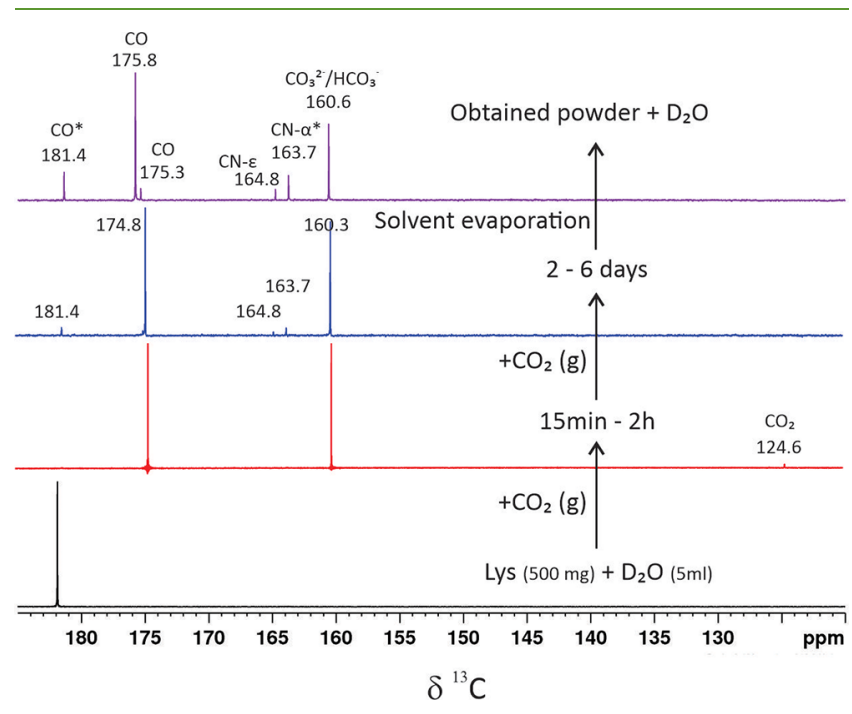

Figure 3. ${ }^{13} \mathrm{C}$ NMR spectra of $\mathrm{L}$-lysine solubilized in $\mathrm{D}_{2} \mathrm{O}$ (black spectrum), bubbling $\mathrm{CO}_{2}(\mathrm{~g})$ into the aqueous L-lysine for $15 \mathrm{~min}$ to 2 $\mathrm{h}$ (red spectrum), bubbling $\mathrm{CO}_{2}(\mathrm{~g})$ into the aqueous solution for 26 days (blue spectrum), and after the solvent evaporation (purple spectrum).

reduction could also be attributed to $\mathrm{CO}_{2}$ diffusion limitations, which are minimized in industrial $\mathrm{CO}_{2}$ absorption processes by using dedicated gas-liquid contacting equipment. ${ }^{11-13}$ The carbon signals related to the carbamate bond formation start to appear only after $48 \mathrm{~h}$ of reaction (Figure 3, blue spectrum, peaks at $\delta=164.8$ and $163.7 \mathrm{ppm}$ ). Alternatively, a mixture of L-lysine ammonium $\alpha$ - and $\varepsilon$-carbamates could be isolated after removing water under reduced pressure, which is yet known to be an energy-intensive process (Figure 3, purple spectrum).

The ${ }^{13} \mathrm{C}$ NMR analysis of a pure sample of L-lysine ammonium $\varepsilon$-carbamate also displays a small peak corresponding to the formation of carbonate/bicarbonate ions $(\delta=161$ ppm) almost immediately after dissolution in $\mathrm{D}_{2} \mathrm{O}$, confirming that the formation of ammonium carbamates of L-lysine is a reversible process in water. ${ }^{44,45}$

Structural Analysis by Liquid NMR. The rapid formation of carbonate/bicarbonate ions after the solubilization of $\mathrm{L}^{-}$ lysine ammonium carbamates in $\mathrm{D}_{2} \mathrm{O}$ did not prevent homoand heteronuclear 2D liquid NMR measurements to give relevant information on the structure of L-lysine ammonium carbamates in $\mathrm{D}_{2} \mathrm{O}$. Contrary to ${ }^{1} \mathrm{H} \rightarrow{ }^{13} \mathrm{C} \mathrm{CP}$ MAS NMR experiment, the ${ }^{1} \mathrm{H} /{ }^{13} \mathrm{C}$ HMBC measurement of L-lysine ammonium $\varepsilon$-carbamate after solubilization in $\mathrm{D}_{2} \mathrm{O}$ (Figure 4) depicted two carbon signals at $\delta=164$ and $165 \mathrm{ppm}$, indicating the formation of two different carbamate bonds. This difference could be explained by migrations of the carbamate bonds between $\varepsilon-\mathrm{NH}_{2}$ and $\alpha-\mathrm{NH}_{2}$ through the intermediate formation of solubilized $\mathrm{CO}_{2}$. The two cross- 


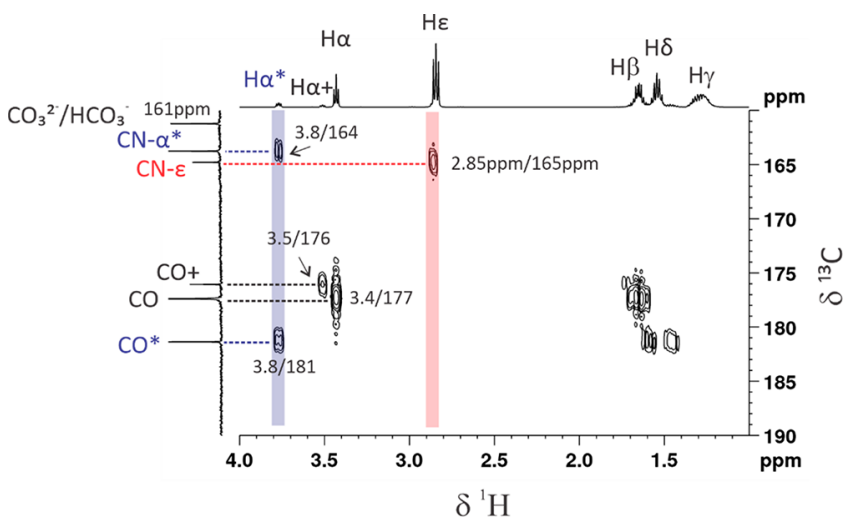

Figure 4. ${ }^{1} \mathrm{H} /{ }^{13} \mathrm{C}$ HMBC spectrum of L-lysine ammonium $\alpha$ - and $\varepsilon$ carbamates obtained by milling. The formation of the $\alpha$-carbamate ion is indicated by the two cross-peaks at $\delta=3.8$ (labeled $\mathrm{H} \alpha^{*}$ ) with the carbamyl carbon signal at $\delta=164 \mathrm{ppm}$ (labeled $\mathrm{CN}-\alpha^{*}$ ) and the carboxylate carbon at $\delta=181 \mathrm{ppm}\left(\mathrm{CO}^{*}\right)$. The cross-peak between $\mathrm{H} \alpha(\delta=3.4 \mathrm{ppm})$ and the carboxylate carbon $\mathrm{CO}(\delta=177 \mathrm{ppm})$ is related to the formation of an $\alpha$-ammonium ion. The presence of an $\varepsilon$-carbamate ion is confirmed by the cross-peak between $\mathrm{H} \varepsilon(\delta=2.85$ $\mathrm{ppm})$ and the carbamyl signal at $\delta=165 \mathrm{ppm}(\mathrm{CN}-\varepsilon)$.

peaks of the proton signal at $\delta=3.8$ (labeled $\mathrm{H} \alpha^{*}$ ) with the carbamyl carbon signal at $\delta=164 \mathrm{ppm}$ (labeled $\mathrm{CN}-\alpha^{*}$ ) and the carboxylate carbon at $\delta=181 \mathrm{ppm}\left(\mathrm{CO}^{*}\right)$ indicate the formation of the $\alpha$-carbamate ion. Furthermore, the cross-peak between the proton $\mathrm{H} \alpha(\delta=3.4 \mathrm{ppm})$ and the carboxylate carbon $\mathrm{CO}(\delta=177 \mathrm{ppm})$ is attributed to the formation of an $\alpha$-ammonium ion. On the other hand, the cross-peak between the proton signal at $\delta=2.85 \mathrm{ppm}(\mathrm{H} \varepsilon)$ and the carbamyl signal at $\delta=165 \mathrm{ppm}(\mathrm{CN}-\varepsilon)$ indicates the formation of an $\varepsilon$ carbamate ion. These measurements suggest that, in water, both the $\alpha$ - and $\varepsilon$-carbamates are individually formed in two different lysine molecules, as depicted in Figure $1 \mathrm{~b}$. The proton-carbon cross-peak at $\delta=3.5 \mathrm{ppm}\left(\mathrm{H}_{\alpha}+\right) / 176 \mathrm{ppm}$ $(\mathrm{CO}+)$ is attributable to the protons exchange between $\alpha$ amino and carboxylate groups $\left({ }^{+} \mathrm{H}_{3} \mathrm{~N}-\mathrm{C}_{\alpha} \mathrm{HR}-\mathrm{COO}^{-} \leftrightarrow\right.$ $\mathrm{H}_{2} \mathrm{~N}-\mathrm{C}_{\alpha} \mathrm{HR}-\mathrm{COOH}$ ) indicated by the minimal chemical shift between both carboxylate groups $(\Delta \delta=1 \mathrm{ppm})$.

Influence of Liquid Additives. Next, we investigated the influence of liquid additives on the formation of $\mathrm{L}$-lysine ammonium $\varepsilon$-carbamate by ball-milling. Indeed, previous studies on solution-based reactions showed that the nature of the solvent could influence the selectivity outcome of the reaction between amino-functionalized samples and $\mathrm{CO}_{2}$ in solution. ${ }^{8,46}$ In mechanochemistry, the use of a liquid additive during milling, known as liquid-assisted grinding (LAG), is capable of sharply accelerating the reactions, improving the crystallinity of the resulting powder products and modifying the polymorphic outcome. ${ }^{47-53}$ In order to facilitate the comparison with other LAG processes, the $\eta$ parameter was utilized, which is defined by the ratio of the volume of the liquids used $(\mu \mathrm{L})$ to the total mass of solids $(\mathrm{mg}){ }^{47}$ In our case, adding a small amount of water $\left(50 \mu \mathrm{L}\right.$ of $\mathrm{H}_{2} \mathrm{O} / 500 \mathrm{mg}$ of L-lysine; $\eta=0.1 \mu \mathrm{L} / \mathrm{mg}$ ) led to the formation of the carbamate bond on the two positions, as indicated by the peak at $\delta=165 \mathrm{ppm}$ and the shoulder at $\delta=161 \mathrm{ppm}$ in ${ }^{1} \mathrm{H} \rightarrow{ }^{13} \mathrm{C}$ CP MAS measurements (Figure 1, blue spectrum). In addition, ${ }^{1} \mathrm{H} \rightarrow{ }^{15} \mathrm{~N}$ CP MAS measurement displayed two peaks at $\delta=$ 88 and $74 \mathrm{ppm}$ in the carbamate region (Figure 2, blue spectrum). The formation of the carbamates at both the $\alpha$ - and
$\varepsilon-\mathrm{NH}_{2}$ positions even when minimal amounts of water are present during the synthesis is a clear indication that the total absence of "free" water during milling (as opposed to crystallized water present in the starting material) is necessary to have a selective formation of the carbamate at the $\varepsilon$ - $\mathrm{NH}_{2}$ position. Contrary to neat-milling, grinding with protophilic solvents such as water or DMSO as liquid assistants provided L-lysine ammonium carbamates with a higher crystallinity (Figure S5, red and blue patterns) than the products obtained by neat-milling (Figure S5, black pattern), as indicated by powder X-ray diffraction measurements. However, milling with nonprotophilic $\mathrm{CH}_{2} \mathrm{Cl}_{2}$ as a liquid assistant did not improve the crystallinity of the final powder (Figure S5, cyan pattern).

Reactivity in the Solid State without Agitation. To understand the role of agitation during the milling process, gaseous $\mathrm{CO}_{2}$ was flushed over powders of L-lysine for $4 \mathrm{~h}$ without any agitation, followed by storing the powders under a $\mathrm{CO}_{2}$ atmosphere at ambient pressure for 15 days. ${ }^{1} \mathrm{H} \rightarrow{ }^{13} \mathrm{C}$ CP MAS NMR measurements of the resulting powder indicated the incomplete conversion of L-lysine to the corresponding ammonium carbamate, as indicated by the tiny peak at $\delta=165 \mathrm{ppm}$ (Figure 1, green spectrum). This latter result indicates that the reactivity between L-lysine and $\mathrm{CO}_{2}$ leads to a "negative feedback", as theorized by Boldyreva, ${ }^{28}$ confirming that the grinding process is necessary for the rapid conversion of L-lysine to the corresponding ammonium carbamate.

Stability and Reversibility. Next, the thermal stability of L-lysine ammonium $\varepsilon$-carbamate and the reversibility of the formation of this carbamate were assessed. After being stored under ambient conditions for several months, L-lysine ammonium $\varepsilon$-carbamate showed no analytical differences with the freshly prepared compounds, indicating its good stability under ambient conditions. The thermal treatment of $\mathrm{L}$ lysine ammonium $\varepsilon$-carbamate at $175{ }^{\circ} \mathrm{C}$ for $1 \mathrm{~h}$ or the addition of a few drops of aqueous $\mathrm{DCl}$ cleaved the carbamate bond. The release of gaseous $\mathrm{CO}_{2}$ was indicated by the continuous formation of bubbles while adding aqueous $\mathrm{DCl}$ on the aqueous solutions of L-lysine ammonium $\boldsymbol{\varepsilon}$-carbamate, in addition to the disappearance of the carbamate signals in the ${ }^{13} \mathrm{C}$ NMR spectra (Figure 5, red spectrum) (by thermal treatment at $175{ }^{\circ} \mathrm{C}$, Figure 5, green spectrum). The comparisons of ${ }^{13} \mathrm{C}$ NMR spectra in Figure S6 indicate the presence of small quantities of nonidentified products after the $\mathrm{DCl}$ treatments, while these products are present in smaller quantities after the thermal treatment. The latter spectrum is similar to the ${ }^{13} \mathrm{C}$ NMR spectrum of L-lysine, which indicates that the carbamate formation by milling L-lysine with $\mathrm{CO}_{2}$ is a reversible process upon heating at $175{ }^{\circ} \mathrm{C}$. Of note, this temperature is superior to the one used in classical absorbers that reversibly produce $\mathrm{CO}_{2}$ at temperatures between 100 to $120{ }^{\circ} \mathrm{C} .{ }^{10}$

Mechanism. In the literature, two mechanisms were mainly proposed to describe the solution-based reactions between alkylamines and alkanolamines with $\mathrm{CO}_{2}$ : the termolecular mechanism and zwitterion mechanism. ${ }^{54-56}$ The latter mechanism is commonly used to explain the $\mathrm{CO}_{2}$ reaction with amino acids. ${ }^{20,22,23}$ In this proposed reaction pathway (Scheme 2), the carbamate formation is explained by the nucleophilic attack of the nitrogen on the electrophilic carbon of the carbon dioxide molecule, forming a zwitterion (Scheme 2, eq 1). Second, another amino-functionalized molecule acts as a weak base for the formation of an ammonium carbamate 


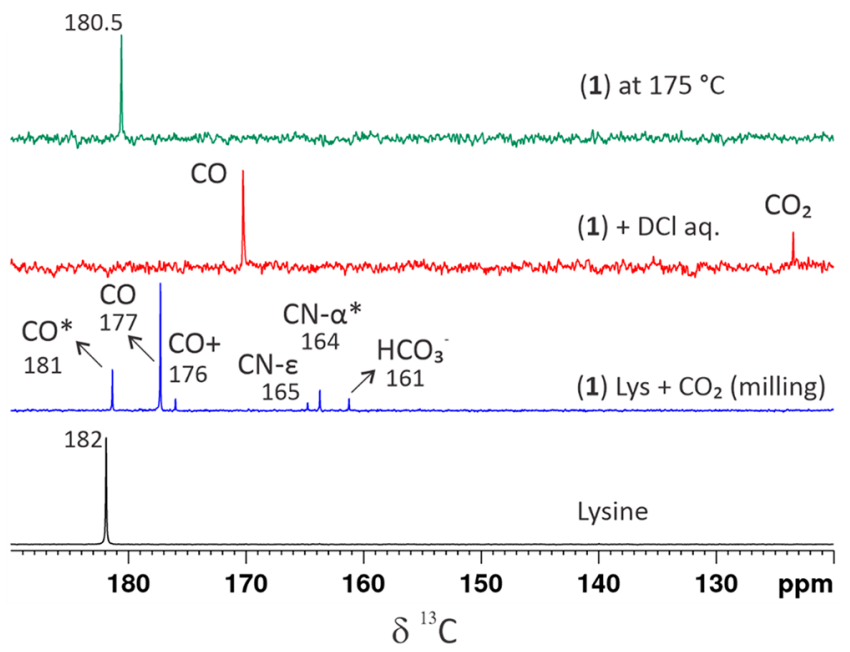

Figure 5. ${ }^{13} \mathrm{C}$ NMR spectra of L-lysine ammonium $\varepsilon$-carbamate assynthesized and after post-treatment (in $\mathrm{D}_{2} \mathrm{O}$ ). L-Lysine (black spectrum) depicts the carbon signal of the carboxylate group $(\delta=182$ $\mathrm{ppm})$. The carbamate bond of L-lysine ammonium $\varepsilon$-carbamate obtained by milling (blue spectrum) is cleaved after treatments by adding aqueous $\mathrm{DCl}$ (red spectrum) or by thermal treatment at 175 ${ }^{\circ} \mathrm{C}$ for $1 \mathrm{~h}$ (green spectrum).

Scheme 2. Proposed Zwitterion Mechanism for the Formation of Ammonium Carbamate by Milling L-lysine (Introduced as $\mathrm{R}-\mathrm{NH}_{2}$ ) under a $\mathrm{CO}_{2}$ Atmosphere ${ }^{a}$

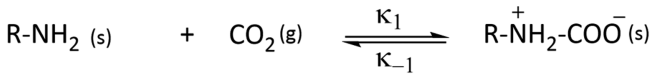

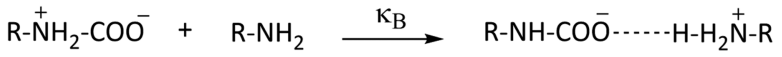

${ }^{a}$ Nucleophilic attack of the nitrogen atom $\left(\mathrm{R}-\mathrm{NH}_{2}\right)$ on the electrophilic carbon of $\mathrm{CO}_{2}$, forming a zwitterion (eq 1). Another nitrogen atom $\left(\mathrm{R}-\mathrm{NH}_{2}\right)$ acts as a weak base, leading to the formation of an ammonium carbamate ion pair (eq 2).

ion pair (Scheme 2, eq 2). Such a mechanism could also explain the formation of the carbamates obtained by milling in the absence or quasi-absence of added liquids.

In solution-based reactions, the nature of the solvent can influence the selectivity outcome of the reaction between amino-functionalized samples and $\mathrm{CO}_{2}$ in solution. ${ }^{8,46}$ It has been reported that carbamic acids of amines and lysine peptides are selectively generated in polar aprotic solvents. ${ }^{46,20}$ For our experiments, using LAG conditions of such solvents (dimethyl sulfoxide (DMSO) and dichloromethane (DCM)) did not lead to carbamic acids, only to the formation of ammonium carbamates of L-lysine, as indicated by ${ }^{13} \mathrm{C}$ NMR spectra (Figure S7). The latter result can be rationalized by the poor solubility of L-lysine in the organic solvents, taking into account that the previously reported experiments were performed on $\alpha$-amino acids completely solubilized in organic solvents.

Although the presence of an organic liquid additive does not seem to influence the outcome of the reaction, water has a critical influence on the course of the reaction. While neatmilling regioselectively produces the carbamate at the $\varepsilon-\mathrm{NH}_{2}$ position, adding a small amount of water during milling $(\eta=$ $0.1 \mu \mathrm{L} / \mathrm{mg}$ ) led to the formation of the carbamate bond on both the $\alpha$ - and the $\varepsilon-\mathrm{NH}_{2}$ positions. These carbamates products are confirmed by ${ }^{13} \mathrm{C}$ NMR analyses, where the partial conversion to carbonate/bicarbonate anions is also observed after solubilizing the powder sample in water (Scheme 3, eq 3, and Figure 5, blue spectrum). In contrast,

Scheme 3. Reactions for the Conversion of Carbamate to Carbonate/Bicarbonate (eq 3), the Formation of Ammonium-Bicarbonates by Dissolving Gaseous $\mathrm{CO}_{2}$ in Aqueous Amine-Containing Substrate (eq 4), and the Formation of Bicarbonate by Dissolving $\mathrm{CO}_{2}$ in Water (eq 5)

$$
\begin{aligned}
& \mathrm{R}-\mathrm{NH}-\mathrm{CO} \overline{-}+\mathrm{H}_{2} \mathrm{O} \rightleftharpoons \mathrm{R}-\mathrm{NH}_{2}+\mathrm{HCO}_{3}^{-} \\
& \mathrm{R}-\mathrm{NH}_{2}+\mathrm{H}_{2} \mathrm{O}+\mathrm{CO}_{2}(\mathrm{~g}) \rightleftharpoons \mathrm{HCO}_{3}^{-} \cdots \cdot-\cdot-\mathrm{H}_{2} \stackrel{+}{\mathrm{N}}-\mathrm{R}
\end{aligned}
$$

$$
\mathrm{CO}_{2}(\mathrm{~g})+\overline{\mathrm{OH}} \rightleftharpoons \mathrm{HCO}_{3}^{-}
$$

bubbling gaseous $\mathrm{CO}_{2}$ into a solution of L-lysine in water leads first to the formation of carbonate/bicarbonate anions (Scheme 3, eq 4) and later to the formation of carbamate compounds (2-6 days). Overall, it is strongly suggested that the absence of the added water during neat-milling prevents the competitive formation of the carbonate/bicarbonate anions, which would explain the much faster formation of the carbamate compounds by milling in comparison to during synthesis in water. Comparatively, the rapid appearance (few minutes) of a precipitate of L-lysine ammonium $\varepsilon$-carbamate after bubbling $\mathrm{CO}_{2}$ in a solution of L-lysine in a 1:5 mixture of water/methanol might indicate that the precipitation mechanism prevails over the formation of the carbonate/bicarbonate anions.

Environmental Impact. Finally, the production of waste by the three protocols was compared (neat-milling, synthesis in water, and synthesis in water/MeOH). The complete $E$ factor (cEF) was calculated for each of these three approaches, of which the values are reported in Table $1 .^{57,58}$ The cEF is

Table 1. Complete E Factors for the Synthesis of L-Lysine Ammonium Carbamates by Neat Milling, Synthesis in Water, and Synthesis in Water/Methanol ${ }^{a}$

\begin{tabular}{lc}
\multicolumn{1}{c}{ type of synthesis } & complete $E$ factor $(\mathrm{cEF})$ \\
neat-milling & $0.4(0)^{b}$ \\
synthesis in water & $22.5(0.9)^{c}$ \\
synthesis in water/methanol & $15.0(0.9)^{c}$
\end{tabular}

${ }^{a}$ See the Supporting Information for details of the calculations. ${ }^{b}$ Calculated assuming $100 \%$ recycling of $\mathrm{CO}_{2} \cdot{ }^{c}$ Calculated assuming $100 \%$ recycling of $\mathrm{CO}_{2}$ and recycling of the solvent with $10 \%$ loss.

defined as the amount of waste divided by the amount of final product. Contrary to the simple $E$ factor ( $\mathrm{sEF}$ ), the cEF takes into account water and all organic solvents, assuming no recycling. Thus, the neat-milling process displays a $\mathrm{cEF}$ of 0.4 , while the two solvent-based processes have a much higher $\mathrm{cEF}$ of 22.5 and 15.0, for synthesis in water and in water/MeOH, respectively.

However, these figures were obtained while the $\mathrm{CO}_{2}$ quantities were not optimized in any of the three processes, possibly leading to overvalued $\mathrm{cEF}$ values. Therefore, to 
facilitate a comparison between the three described protocols, a second set of $E$ factors was calculated, where the $\mathrm{CO}_{2}$ quantity used for the calculation was the exact quantity of $\mathrm{CO}_{2}$ ending in the lysine ammonium carbamate (considering excess $\mathrm{CO}_{2}$ could be $100 \%$ recycled). Additionally, an extra assumption was applied, considering that the solvents used could be recycled with a $10 \%$ loss. In these conditions, the $\mathrm{cEF}$ value was still much lower for the neat-milling process ( $\mathrm{cEF}=$ $0)$ than for the solvent-based processes $(\mathrm{cEF}=0.9)$. Overall, these cEF figures clearly show that neat-milling is the process that enables the lowest production of waste, and this superiority can be attributed to the absence of a bulk solvent during neat-milling.

\section{CONCLUSION}

L-Lysine ammonium $\varepsilon$-carbamate can be easily, rapidly, and selectively produced in quantitative yields by the solid-gas mechanochemical reaction of L-lysine with $\mathrm{CO}_{2}$. While the same regioselectivity could be obtained by performing the synthesis in a water/methanol mixture, synthesis by neatmilling discarded the use of the highly toxic methanol. As all atoms of the chemicals used end up in the product, neatmilling is a process that produces no waste (except an excess of $\mathrm{CO}_{2}$ ), leading to an $E$ factor of 0 , well below the other classical processes. The process is highly robust, as the analytically pure carbamate was formed in a wide range of operational conditions (reaction time, rotational speed, and milling material). In addition, this milling approach was much faster than synthesis by bubbling $\mathrm{CO}_{2}$ into a solution of $\mathrm{L}$-lysine in water, most probably due to the absence of the competitive formation of carbonate/bicarbonate anions. Overall, the present work introduces a solid-gas reaction enabled by mechanochemistry as a rapid, regioselective, and clean method for the chemical conversion of gaseous $\mathrm{CO}_{2}$ into L-lysine ammonium $\varepsilon$-carbamate via its direct and solvent-free reaction with L-lysine. This study opens doors to future uses of other innocuous amines as efficient sorbents for $\mathrm{CO}_{2}$ sequestration under solvent-free mechanochemical conditions, which are currently under investigation in our laboratory.

\section{ASSOCIATED CONTENT}

\section{SI Supporting Information}

The Supporting Information is available free of charge at https://pubs.acs.org/doi/10.1021/acssuschemeng.0c00217.

Experimental protocols, liquid NMR spectra, PXRD data, elemental analyses, and thermal analysis measurements (PDF)

\section{AUTHOR INFORMATION}

\section{Corresponding Author}

Thomas-Xavier Métro - Centre National de la Recherche Scientifique (CNRS), Ecole Nationale Supérieure de Chimie de Montpellier (ENSCM), Institut des Biomolecules Max Mousseron (IBMM), Univ Montpellier, Montpellier, France; (1) orcid.org/0000-0003-2280-3595; Email: thomasxavier.metro@umontpellier.fr

\section{Authors}

Abdal-Azim Al-Terkawi - Centre National de la Recherche Scientifique (CNRS), Ecole Nationale Supérieure de Chimie de Montpellier (ENSCM), Institut des Biomolecules Max
Mousseron (IBMM), Univ Montpellier, Montpellier, France; (1) orcid.org/0000-0001-8829-5699

Frédéric Lamaty - Centre National de la Recherche Scientifique (CNRS), Ecole Nationale Supérieure de Chimie de Montpellier (ENSCM), Institut des Biomolecules Max Mousseron (IBMM), Univ Montpellier, Montpellier, France; 다. orcid.org/ 0000-0003-2213-9276

Complete contact information is available at: https://pubs.acs.org/10.1021/acssuschemeng.0c00217

\section{Funding}

The Centre National de la Recherche Scientifique (CNRS), CNRS National Institute of Chemistry (grant to T.-X.M. through EMERGENCE@INC2018 call for proposals), and Université de Montpellier are acknowledged for their financial support.

\section{Notes}

The authors declare no competing financial interest.

\section{ACKNOWLEDGMENTS}

We thank the following colleagues for technical support: Aurélien Lebrun and Karine Parra (liquid NMR), Philippe Gaveau and Emmanuel Fernandez (MAS NMR), Amine Geneste and Romain Tavernier (thermal analysis), Dominique Granier (powder XRD), and Magalie Lefeuvre (elemental analysis).

\section{REFERENCES}

(1) Masson-Delmotte, V.; Zhai, P.; Pörtner, H.-O.; Roberts, D.; Skea, J.; Shukla, P. R.; Pirani, A.; Moufouma-Okia, W.; Péan, C.; Pidcock, R.; Connors, S.; Matthews, J. B. R.; Chen, Y.; Zhou, X.; Gomis, M. I.; Lonnoy, E.; Maycock, T.; Tignor, M.; Waterfield, T. Global Warming of $1.5^{\circ} \mathrm{C}$ : An IPCC Special Report; Intergovernmental Panel on Climate Change, 2018; Vol. 265, pp 37-46.

(2) Dell'Amico, D. B.; Calderazzo, F.; Labella, L.; Marchetti, F.; Pampaloni, G. Converting Carbon Dioxide into Carbamato Derivatives. Chem. Rev. 2003, 103 (10), 3857-3898.

(3) Sakakura, T.; Choi, J. C.; Yasuda, H. Transformation of Carbon Dioxide. Chem. Rev. 2007, 107 (6), 2365-2387.

(4) Riduan, S. N.; Zhang, Y. Recent Developments in Carbon Dioxide Utilization under Mild Conditions. Dalton Trans. 2010, 39 (14), 3347-3357.

(5) Aresta, M. Carbon Dioxide as a Direct Chemical Feedstock; Aresta, M., Ed.; Wiley-VCH Verlag GmbH \& Co. KGaA.: Weinheim, Germany, 2010.

(6) Liu, Q.; Wu, L.; Jackstell, R.; Beller, M. Using Carbon Dioxide as a Building Block in Organic Synthesis. Nat. Commun. 2015, 6, 1-15.

(7) Song, Q.-W.; Zhou, Z.-H.; He, L.-N. Efficient, Selective and Sustainable Catalysis of Carbon Dioxide. Green Chem. 2017, 19 (16), 3707-3728.

(8) Masuda, K.; Ito, Y.; Horiguchi, M.; Fujita, H. Studies on the Solvent Dependence of the Carbamic Acid Formation from $\omega$-(1Naphthyl)Alkylamines and Carbon Dioxide. Tetrahedron 2005, 61 (1), 213-229.

(9) Rudkevich, D. M.; Xu, H. Carbon Dioxide and Supramolecular Chemistry. Chem. Commun. 2005, 1 (21), 2651-2659.

(10) Rochelle, G. T. Amine Scrubbing for $\mathrm{CO}_{2}$ Capture. Science 2009, 325 (5948), 1652-1654.

(11) MacDowell, N.; Florin, N.; Buchard, A.; Hallett, J.; Galindo, A.; Jackson, G.; Adjiman, C. S.; Williams, C. K.; Shah, N.; Fennell, P. An Overview of $\mathrm{CO}_{2}$ Capture Technologies. Energy Environ. Sci. 2010, 3 (11), 1645-1669.

(12) Raynal, L.; Bouillon, P. A.; Gomez, A.; Broutin, P. From MEA to Demixing Solvents and Future Steps, a Roadmap for Lowering the 
Cost of Post-Combustion Carbon Capture. Chem. Eng. J. 2011, 171, $742-752$.

(13) Dutcher, B.; Fan, M.; Russell, A. G. Amine-Based $\mathrm{CO}_{2}$ Capture Technology Development from the Beginning of 2013-A Review. ACS Appl. Mater. Interfaces 2015, 7 (4), 2137-2148.

(14) Heldebrant, D. J.; Koech, P. K.; Glezakou, V.-A.; Rousseau, R.; Malhotra, D.; Cantu, D. C. Water-Lean Solvents for Post-Combustion $\mathrm{CO}_{2}$ Capture: Fundamentals, Uncertainties, Opportunities, and Outlook. Chem. Rev. 2017, 117 (14), 9594-9624.

(15) Norwegian Institute of Public Health (NIPH). Health Effects of Amines and Derivatives Associated with $\mathrm{CO}_{2}$ Capture: Nitrosamines and Nitramines; NIPH, 2011; pp 1-15.

(16) Ghayur, A.; Verheyen, T. V.; Meuleman, E. Biological and Chemical Treatment Technologies for Waste Amines from $\mathrm{CO}_{2}$ Capture Plants. J. Environ. Manage. 2019, 241, 514-524.

(17) Monoethanolamine (MEA), the most widely used amine to capture $\mathrm{CO}_{2}$ at the industrial scale, is corrosive and highly toxic according to regulation EC No. 1272/2008.

(18) Zhang, J.; Zhang, S.; Dong, K.; Zhang, Y.; Shen, Y.; Lv, X. Supported Absorption of $\mathrm{CO}_{2}$ by Tetrabutylphosphonium Amino Acid Ionic Liquids. Chem. - Eur. J. 2006, 12, 4021-4026.

(19) Stastny, V.; Anderson, A.; Rudkevich, D. M. Supramolecular Structures from Lysine Peptides and Carbon Dioxide. J. Org. Chem. 2006, 71, 8696-8705.

(20) Yamamoto, Y.; Hasegawa, J. Y.; Ito, Y. Kinetic Investigation on Carbamate Formation from the Reaction of Carbon Dioxide with Amino Acids in Homogeneous Aqueous Solution. J. Phys. Org. Chem. 2012, 25, 239-247.

(21) Saravanamurugan, S.; Kunov-kruse, A. J.; Fehrmann, R.; Riisager, A. Amine-Functionalized Amino Acid-Based Ionic Liquids as Efficient and High-Capacity Absorbents for $\mathrm{CO}_{2}$. ChemSusChem 2014, 7, 897-902.

(22) Shen, S.; Yang, Y.; Bian, Y.; Zhao, Y. Kinetics of $\mathrm{CO}_{2}$ Absorption into Aqueous Basic Amino Acid Salt: Potassium Salt of Lysine Solution. Environ. Sci. Technol. 2016, 50 (4), 2054-2063.

(23) Hu, G.; Smith, K. H.; Liu, L.; Kentish, S. E.; Stevens, G. W. Reaction Kinetics and Mechanism between Histidine and Carbon Dioxide. Chem. Eng. J. 2017, 307, 56-62.

(24) Schimming, V.; Hoelger, C.-G.; Buntkowsky, G.; Sack, I.; Fuhrhop, J.-H.; Rocchetti, S.; Limbach, H.-H. Evidence by ${ }^{15} \mathrm{~N}$ CPMAS and ${ }^{15} \mathrm{~N}-{ }^{13} \mathrm{C}$ REDOR NMR for Fixation of Atmospheric $\mathrm{CO}_{2}$ by Amino Groups of Biopolymers in the Solid State. J. Am. Chem. Soc. 1999, 121 (20), 4892-4893.

(25) Dos, A.; Schimming, V.; Tosoni, S.; Limbach, H.-H. Acid-Base Interactions and Secondary Structures of Poly-l-Lysine Probed by ${ }^{15} \mathrm{~N}$ and ${ }^{13} \mathrm{C}$ Solid State NMR and Ab Initio Model Calculations. J. Phys. Chem. B 2008, 112 (49), 15604-15615.

(26) Kaupp, G. Mechanochemistry: The Varied Applications of Mechanical Bond-Breaking. CrystEngComm 2009, 11, 388-403.

(27) James, S. L.; Adams, C. J.; Bolm, C.; Braga, D.; Collier, P.; Friščić, T.; Grepioni, F.; Harris, K. D. M.; Hyett, G.; Jones, W.; Krebs, A.; Mack, J.; Maini, L.; Orpen, A. G.; Parkin, I. P.; Shearouse, W. C.; Steed, J. W.; Waddell, D. C. Mechanochemistry: Opportunities for New and Cleaner Synthesis. Chem. Soc. Rev. 2012, 41, 413-447.

(28) Boldyreva, E. Mechanochemistry of Inorganic and Organic Systems: What Is Similar, What Is Different? Chem. Soc. Rev. 2013, 42 (18), 7719-7738.

(29) Friščić, T.; Mottillo, C.; Titi, H. M. Mechanochemistry for Synthesis. Angew. Chem., Int. Ed. 2020, 59 (3), 1018-1029.

(30) Beillard, A.; Bantreil, X.; Métro, T.-X.; Martinez, J.; Lamaty, F. Alternative Technologies That Facilitate Access to Discrete Metal Complexes. Chem. Rev. 2019, 119 (12), 7529-7609.

(31) Hernández, J. G.; Bolm, C. Altering Product Selectivity by Mechanochemistry. J. Org. Chem. 2017, 82 (8), 4007-4019.

(32) Bolm, C.; Hernández, J. G. Mechanochemistry of Gaseous Reactants. Angew. Chem., Int. Ed. 2019, 58 (11), 3285-3299.

(33) Beillard, A.; Métro, T.-X.; Bantreil, X.; Martinez, J.; Lamaty, F. $\mathrm{Cu}(0), \mathrm{O}_{2}$ and Mechanical Forces: A Saving Combination for
Efficient Production of $\mathrm{Cu}-\mathrm{NHC}$ Complexes. Chem. Sci. 2017, 8 (2), 1086-1089.

(34) Mori, S.; Xu, W.-C.; Ishidzuki, T.; Ogasawara, N.; Imai, J.; Kobayashi, K. Mechanochemical Activation of Catalysts for $\mathrm{CO}_{2}$ Methanation. Appl. Catal., A 1996, 137 (2), 255-268.

(35) Phung, C.; Ulrich, R. M.; Ibrahim, M.; Tighe, N. T. G.; Lieberman, D. L.; Pinhas, A. R. The Solvent-Free and Catalyst-Free Conversion of an Aziridine to an Oxazolidinone Using Only Carbon Dioxide. Green Chem. 2011, 13, 3224-3229.

(36) Jeon, I.-Y.; Shin, Y.-R.; Sohn, G.-J.; Choi, H.-J.; Bae, S.-Y.; Mahmood, J.; Jung, S.-M.; Seo, J.-M.; Kim, M.-J.; Wook Chang, D.; Dai, L.; Baek, J.-B. Edge-Carboxylated Graphene Nanosheets via Ball Milling. Proc. Natl. Acad. Sci. U. S. A. 2012, 109 (15), 5588-5593.

(37) Leclaire, J.; Septavaux, J.; Métro, T.-X. Metal Extraction from Supramolecular Solids Obtained by Mechanochemistry. WO/2019/ 053148, September 13, 2018.

(38) Brekalo, I.; Yuan, W.; Mottillo, C.; Lu, Y.; Zhang, Y.; Casaban, J.; Holman, K. T.; James, S. L.; Duarte, F.; Williams, P. A.; Harris, K. D. M.; Friščić, T. Manometric Real-Time Studies of the Mechanochemical Synthesis of Zeolitic Imidazolate Frameworks. Chem. Sci. 2020, 11 (8), 2141-2147.

(39) Tadepally, H. D. Recent Advances in the Industrial Production of L-Lysine by Bacteria. In Recent Developments in Applied Microbiology and Biochemistry; Buddolla, V., Ed.; Academic Press, 2019; pp 97106.

(40) Bru, J. L-Lysine Carbamate. DE2951132A1, July 10, 1980.

(41) Williams, P. A.; Hughes, C. E.; Harris, K. D. M. L-Lysine: Exploiting Powder X-Ray Diffraction to Complete the Set of Crystal Structures of the 20 Directly Encoded Proteinogenic Amino Acids. Angew. Chem., Int. Ed. 2015, 54, 3973-3977.

(42) Williams, P. A.; Hughes, C. E.; Martin, J.; Courvoisier, E.; Buanz, A. B. M.; Gaisford, S.; Harris, K. D. M. Understanding the Solid-State Hydration Behavior of a Common Amino Acid: Identification, Structural Characterization, and Hydration/Dehydration Processes of New Hydrate Phases of L-Lysine. J. Phys. Chem. C 2016, 120, 9385-9392.

(43) Erdemir, D.; Lee, A. Y.; Myerson, A. S. Nucleation of Crystals from Solution: Classical and Two-Step Models. Acc. Chem. Res. 2009, 42 (5), 621-629.

(44) Ciftja, A. F.; Hartono, A.; Svendsen, H. F. Carbamate Formation in Aqueous - Diamine - $\mathrm{CO}_{2}$ Systems. Energy Procedia 2013, 37, 1605-1612.

(45) Lv, B.; Jing, G.; Qian, Y.; Zhou, Z. An Efficient Absorbent of Amine-Based Amino Acid-Functionalized Ionic Liquids for $\mathrm{CO}_{2}$ Capture: High Capacity and Regeneration Ability. Chem. Eng. J. 2016, 289, 212-218.

(46) Stastny, V.; Anderson, A.; Rudkevich, D. M. Supramolecular Structures from Lysine Peptides and Carbon Dioxide. J. Org. Chem. 2006, 71 (23), 8696-8705.

(47) Friščić, T.; Childs, S. L.; Rizvi, S. A. A.; Jones, W. The Role of Solvent in Mechanochemical and Sonochemical Cocrystal Formation: A Solubility-Based Approach for Predicting Cocrystallisation Outcome. CrystEngComm 2009, 11 (3), 418-426.

(48) Friščić, T.; Fábián, L. Mechanochemical Conversion of a Metal Oxide into Coordination Polymers and Porous Frameworks Using Liquid-Assisted Grinding (LAG). CrystEngComm 2009, 11 (5), 743745.

(49) Friščić, T.; Reid, D. G.; Halasz, I.; Stein, R. S.; Dinnebier, R. E.; Duer, M. J. Ion- and Liquid-Assisted Grinding: Improved Mechanochemical Synthesis of Metal-Organic Frameworks Reveals Salt Inclusion and Anion Templating. Angew. Chem., Int. Ed. 2010, 49 (4), 712-715.

(50) Bowmaker, G. A. Solvent-Assisted Mechanochemistry. Chem. Commun. 2013, 49 (4), 334-348.

(51) Hasa, D.; Miniussi, E.; Jones, W. Mechanochemical Synthesis of Multicomponent Crystals: One Liquid for One Polymorph? A Myth to Dispel. Cryst. Growth Des. 2016, 16 (8), 4582-4588.

(52) Al-Terkawi, A.-A.; Scholz, G.; Prinz, C.; Zimathies, A.; Emmerling, F.; Kemnitz, E. Hydrated and Dehydrated Ca- 
Coordination Polymers Based on Benzene-Dicarboxylates: Mechanochemical Synthesis, Structures Refinement, and Spectroscopic Characterization. CrystEngComm 2018, 20, 946-961.

(53) Riss-Yaw, B.; Métro, T.-X.; Lamaty, F.; Coutrot, F. Association of Liquid-Assisted Grinding with Aging Accelerates the Inherently Slow Slipping-on of a Dibenzo-24-Crown-8 over the N-Hydroxysuccinimide Ester of an Ammonium-Containing Thread. RSC Adv. 2019, 9 (37), 21587-21590.

(54) Danckwerts, P. V. The Reaction of $\mathrm{CO}_{2}$ with Ethanolamines. Chem. Eng. Sci. 1979, 34 (4), 443-446.

(55) Donaldson, T. L.; Nguyen, Y. N. Carbon Dioxide Reaction Kinetics and Transport in Aqueous Amine Membranes. Ind. Eng. Chem. Fundam. 1980, 19 (3), 260-266.

(56) Crooks, J. E.; Donnellan, J. P. Kinetics and Mechanism of the Reaction between Carbon Dioxide and Amines in Aqueous Solution. J. Chem. Soc., Perkin Trans. 2 1989, No. 4, 331-333.

(57) Roschangar, F.; Sheldon, R. A.; Senanayake, C. H. Overcoming Barriers to Green Chemistry in the Pharmaceutical Industry - the Green Aspiration Level ${ }^{\mathrm{TM}}$ Concept. Green Chem. 2015, 17 (2), 752768.

(58) Sheldon, R. A. The E Factor 25 Years on: The Rise of Green Chemistry and Sustainability. Green Chem. 2017, 19 (1), 18-43. 